\title{
A LONGITUDINAL STUDY OF PSYCHIATRIC MORBIDITY IN A GENERAL PRACTICE POPULATION
}

\author{
BY
}

\author{
BRIAN COOPER, M.D., D.P.M. \\ Institute of Psychiatry, London, S.E.5 \\ JOHN FRY, M.D., F.R.C.S. \\ General Practitioner, Beckenham, Kent
}

AND

GRAHAM KALTON, M.Sc. (Econ.)

London School of Economics

During the past two decades, the high prevalence of minor psychiatric disorders has been emphasized by the findings of a number of community surveys in Europe and North America (inter alia, EssenMöller, 1956; Pasamanick, Roberts, Lemkau, and Krueger, 1959; Srole, Langner, Michael, Opler, and Rennie, 1962; Leighton, Harding, Macklin, Hughes, and Leighton, 1963; Helgason, 1964). In the United Kingdom, the renaissance of general practice research under the National Health Service (N.H.S.) has fostered a series of investigations in this field, including some large collaborative studies (Watts, 1962; Watts, Cawte, and Kuenssberg, 1964; Shepherd, Cooper, Brown, and Kalton, 1966). The consensus of such enquiries has been that in any one year at least one in 10 of a general practitioner's registered patients will consult him with frank psychiatric symptoms.

By comparison, there has been a dearth of longitudinal studies of psychiatric illness in the community. Our knowledge of the 'natural history' of the neuroses has been gleaned almost entirely from hospital case-series, even though it is widely recognized that they are highly unrepresentative of neurosis in the general population (Kessel and Shepherd, 1962; Cooper, 1966). The scarcity of follow-up studies from general practice is particularly regrettable because of the special opportunity which the family doctor's position affords for charting all those lesser fluctuations of health and social adjustment not adequately revealed by hospital-based surveys.

The reluctance of general practitioners to embark on longitudinal studies is understandable in view of the formidable problems of recording and data analysis, and it may be significant that one of the very few relevant studies so far published developed out of a routine system of recording on punched cards. Using this technique, Fry (1960) was able to segregate and re-examine in 1959 the clinical records of all those of his patients who had attended with a? neurotic illness in 1956. He found that $27 \%$ of the males and $43 \%$ of the females in this patient cohort had required further treatment for neurotic disorders in the follow-up year, and that the proportion tended to increase with age. Moreover, the original 'neurotic' group appeared to have maintained a significantly higher mean consultation rate than the remainder of the practice population, so that, regardless of the overt nature of their complaints, they had remained a relatively heavy burden on the medical services.

While these findings by no means bore out the aphorism 'Once a neurotic, always a neurotic', they pointed to the existence of a nuclear group of chronic or remittent disorders meriting further and more detailed investigation. The present study is an extension of this earlier enquiry, based on the same practice population and employing the same research technique.

\section{Design AND Method}

The practice, which has been described in a number of previous reports (e.g., Fry, 1957) is situated in a residential suburb on the edge of Greater London. The two principals have a registered population of about 7,000 , which has been growing slowly over the years.

Every consultation by each patient in the practice is recorded routinely both on his N.H.S. medical 
record card and on a Cope-Chat punched card (Fry, 1966). At the end of the year, each of 19 possible diagnostic categories recorded for the individual patient is punched on his card, together with a selection of specific diagnoses and a record of any hospital referrals or special investigations. The punched cards for each year are then stored in agesex groups.

The patient cohort chosen for this investigation comprised all those still in the practice at the end of 1963 who had been continuously registered since 1956 or earlier, the nominal list being compiled from the practice age-sex register. For each patient the information contained on the Cope-Chat cards for the years 1957-63 was transcribed onto a single card and thence transferred to I.B.M. machine-punched cards. The data included age, sex, marital status, number of consultations and of hospital referrals annually, and the main diagnostic categories recorded, as well as specific mention of a number of chronic disorders of special interest including peptic ulcer, asthma, coronary disease, hypertension, diabetes, and rheumatoid arthritis.

All psychiatric diagnoses were recorded on the punched cards simply as 'neurosis'. Perusal of a sample of medical record cards confirmed that the great bulk of these conditions had in fact been diagnosed as either anxiety states or depressive reactions, and in processing the data no attempt was made to differentiate the small numbers of psychoses and other types of psychiatric disorder. Since for each illness-episode the diagnostic groups were treated as mutually exclusive, the category of 'neurosis' did not cover psychosomatic conditions or physical illnesses with a neurotic component.

Because of the need to group the patients in convenient age categories, 1960, the central year of the relevant period, was taken as the point from which all individual ages were calculated. Hence patients born in the period 1950-56 were placed in the age-group 4-10, those born in 1940-49 in the age-group 11-20, and so forth.

A number of analyses of the data have been carried out, including the patterns of consultation rates and illness-experience presented by the patient cohort during the seven-year period under scrutiny. The present report is concerned only with the course of identified psychiatric illness and its relation to the level of demand for medical care.

\section{RESUlTS}

\section{Demographic Features of the Patient Cohort}

At the beginning of the survey period, there were 6,346 registered patients. The number who remained in the practice throughout the next seven years, and who thus comprised the cohort under investigation, was 4,243 . Of the remainder, $300(4 \cdot 7 \%)$ were known to have died, $1,760(27.7 \%)$ had moved away, and $43(0.7 \%)$ had transferred to other doctors' lists. Analysis of the statistics, year by year, revealed a fluctuating rate of loss from these various causes, ranging from $3 \%$ to $7 \%$ of the practice population, but with no definite trend over the seven years of the survey. The average annual rate of loss of $5 \%$ of the registered population is low by metropolitan standards, and reflects the type of stable residential suburb in which the practice is situated.

Little difference was found in the rates of patient loss for the two sexes, the proportion remaining after seven years being $66.5 \%$ of males and $67.1 \%$ of females. The rates of loss for the different agegroups, on the other hand, differed widely, as can be seen from Figure 1.

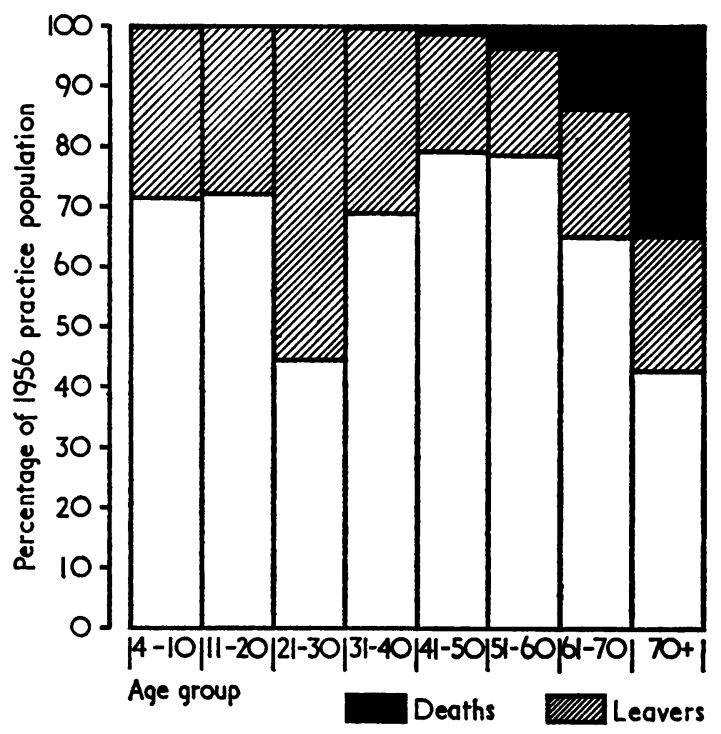

FIG. 1.-Rate of patient loss from practice population over a sevenyear period (1 January 1957 to 31 December 1963).

The conspicuously high rate of loss from causes other than death for the age-group 21-30 was due, presumably, to the high mobility of young adults. Rather surprisingly, it did not result in any serious bias in the age-structure of the cohort, as can be seen from Table $I$. The explanation must reside in the skewed distribution of the initial patient population.

Prevalence and InCePtion Rates for PsYchiatric IllLNess

For each year of the survey period, a one-year prevalence rate could be estimated from the number 
TABLE I

COMPARISON OF THE AGE-SEX DISTRIBUTION OF THE PATIENT COHORT WITH THAT OF THE GENERAL
POPULATION

\begin{tabular}{|c|c|c|c|c|}
\hline \multirow{2}{*}{ Age Group } & \multicolumn{2}{|c|}{ Patient Cohort } & \multicolumn{2}{|c|}{$\begin{array}{l}\text { Great Britain } \\
1961 \text { Census }\end{array}$} \\
\hline & $\underset{\%}{\text { Male }}$ & $\begin{array}{c}\text { Female } \\
\%\end{array}$ & $\underset{\%}{\text { Male }}$ & $\underset{\%}{\text { Female }}$ \\
\hline $\begin{array}{l}4-20 \\
21-40 \\
41-60 \\
\text { Over } 60\end{array}$ & $\begin{array}{l}27 \cdot 6 \\
26 \cdot 1 \\
34 \cdot 4 \\
11 \cdot 9\end{array}$ & $\begin{array}{l}25 \cdot 5 \\
26 \cdot 7 \\
32 \cdot 0 \\
15.8\end{array}$ & $\begin{array}{l}28 \cdot 3 \\
29 \cdot 3 \\
28 \cdot 4 \\
14 \cdot 0\end{array}$ & $\begin{array}{l}25 \cdot 2 \\
27 \cdot 1 \\
27 \cdot 9 \\
19 \cdot 7\end{array}$ \\
\hline Total & $100 \cdot 0$ & $100 \cdot 0$ & $100 \cdot 0$ & $100 \cdot 0$ \\
\hline No. of individuals & 2,025 & 2,218 & $\begin{array}{c}23 \cdot 1 \\
\text { million }\end{array}$ & $\begin{array}{c}24 \cdot 9 \\
\text { million }\end{array}$ \\
\hline
\end{tabular}

of patients who had been given a psychiatric diagnosis at one or more consultations. The mean annual prevalence rate for male patients was 60 per 1,000 at risk, and for females 172 per 1,000 at risk.

The total numbers of male and female patients given psychiatric diagnoses during the survey were 481 and 1,170 respectively, corresponding to sevenyear prevalence rates of 238 and 528 per 1,000 at risk. Thus the number of cases recorded over a seven-year period was approximately four times the mean annual figure for males, and three times the mean annual figure for females. This finding suggests a considerable change, year by year, in the membership of the group diagnosed as 'neurotic'.

In Fig. 2, the mean annual prevalence rates for the survey period are set out by age and sex.

The pattern of distribution shows a marked preponderance of female patients and an increase with age to maximal rates in the fifties. These findings conform broadly both with earlier reported figures from the same practice (Fry, 1957) and with

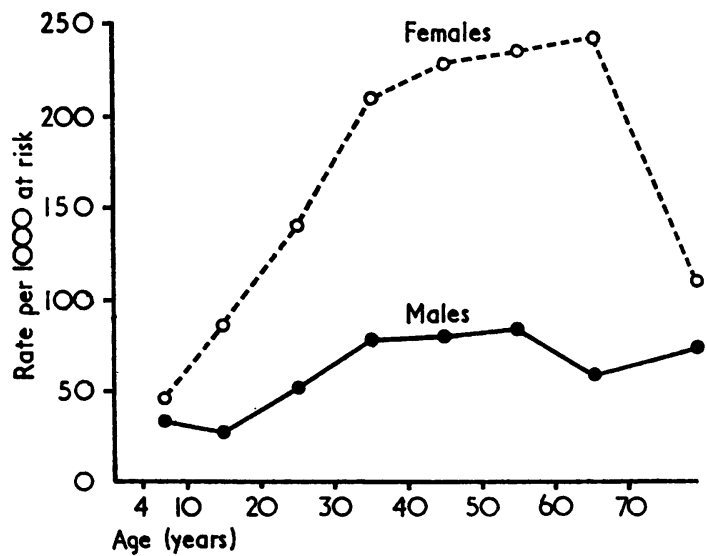

Fro. 2.-Mean annual psychiatric prevalence rates by age and sex. the age-sex rates reported from a survey of London practices conducted in 1961-62 (Shepherd et al., 1966).

There are no grounds for supposing any marked trend either in the incidence or in the course and duration of psychiatric disorder in the general population during the survey period. One might therefore expect to find little change in the annual prevalence rates for this patient cohort other than a small increase due to increasing age. The rates shown in Table II conform to this expectation.

TABLE II

ANNUAL ONE-YEAR PSYCHIATRIC PREVALENCE RATES, PER 1,000 PATIENTS AT RISK, FOR THE PATIENT COHORT, 1957-63

\begin{tabular}{|c|c|c|}
\hline Survey Year & Male & Female \\
\hline $\begin{array}{l}1957 \\
1958 \\
1959 \\
1960 \\
1961 \\
1962 \\
1963\end{array}$ & $\begin{array}{l}62 \\
55 \\
56 \\
53 \\
65 \\
64 \\
67\end{array}$ & $\begin{array}{l}142 \\
169 \\
163 \\
168 \\
193 \\
181 \\
188\end{array}$ \\
\hline No. of patients & 2,025 & 2,218 \\
\hline
\end{tabular}

The pattern of first consultations for psychiatrice illness during the survey period is shown graphically in Figure 3.

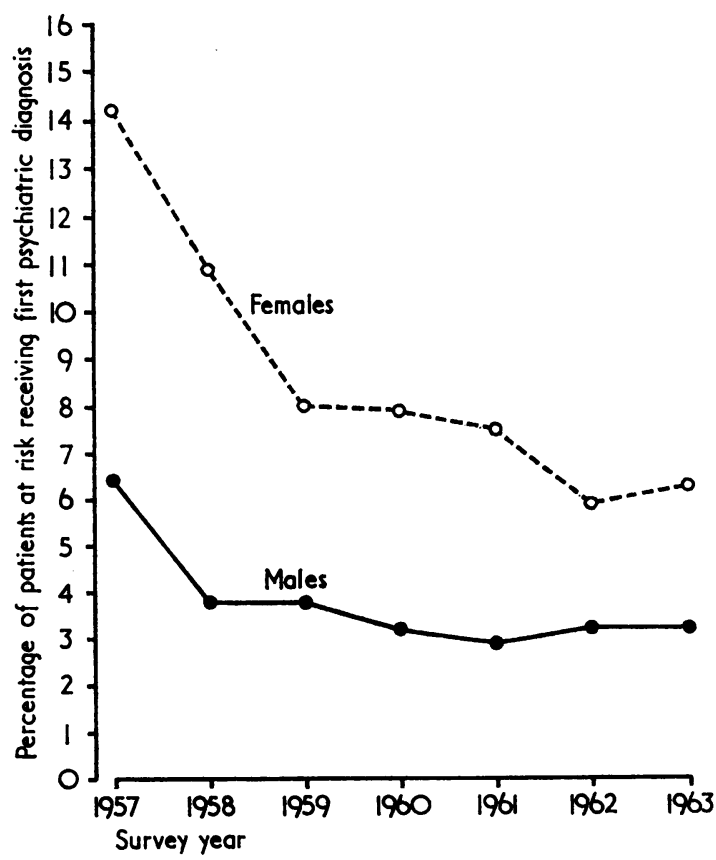

Fio. 3.-Distribution of first psychiatric consultations during survey period, $1957-63$, by sex. 
Here the 1957 figures correspond to one-year prevalence rates, since all psychiatric diagnoses in that year were automatically counted as first diagnoses within the survey period. The rates for 1958 relate only to those patients who had not been given a psychiatric diagnosis in 1957 , the rates for 1959 only to those not given a psychiatric diagnosis during the preceding two years, and so on.

If psychiatric disorders ran a discrete, continuous course, and all patients were equally susceptible, one would expect after 1957 to find no change in inception rates apart from a slight rise due to the ageing effect. In fact, as can be seen from Fig. 3, the rate did not level off for the first three years among the males and for the first five years among the females. The explanation may lie in the remittent nature of psychiatric illness. Presumably the figures for 195861 were inflated by a number of patients who had consulted with psychiatric symptoms in 1956 or earlier, and who were not 'new' cases in the strict sense. From this point of view, the nearest approach to true inception rates are provided by the 1962 and 1963 figures, which do indeed suggest a levelling off for both sexes to a steady annual inception rate.

Taking the mean of the values for 1962 and 1963 as an approximation to the annual psychiatric inception rate, we arrive at a figure of 32 per 1000 males at risk, and of 61 per 1000 females. In Fig. 4 the age distribution of new cases is compared with that for all cases, for these two years.

The graphs suggest that the marked increase in prevalence to a peak at middle age is partly due to an accumulation of chronic or recurrent illness. Moreover, the male : female ratio for inception rates is lower than that for prevalence rates $(1: 2$ compared with $1: 3)$, a finding consistent with a relative excess

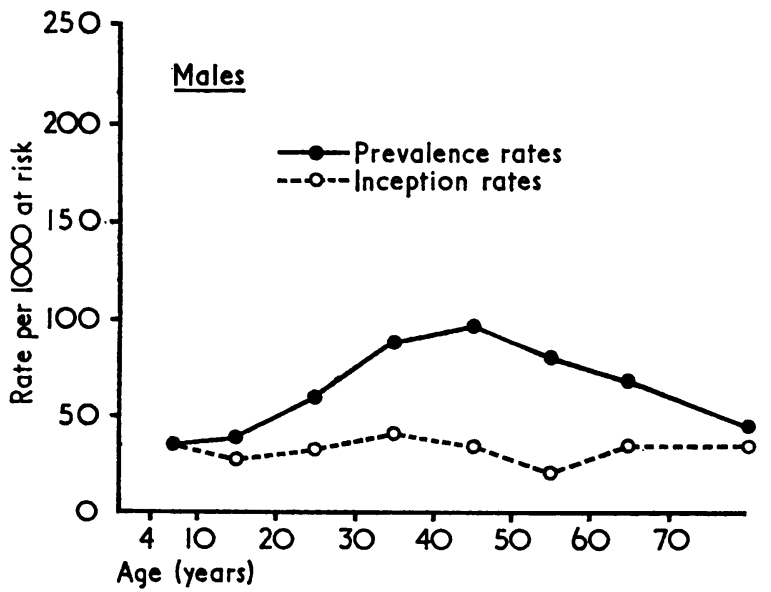

of chronic or relapsing conditions, and hence with a less favourable clinical prognosis, among women.

Since the prevalence of any illness in a defined population is a function of its inception rate and mean duration, an estimate can be made for any one of these variables where the other two are known. In practice, however, the assessment of duration by this method requires too many assumptions to be of much value (Kalton, 1968). In any event, the estimated mean duration of a heterogeneous group of conditions of widely differing course and outcome must be of doubtful significance. More interesting, in the present context, are those variations in the course of psychiatric morbidity which could be charted over the seven years of the survey.

\section{Course of Psychiatric Illness over the Survey PERIOD}

The findings indicate that a large proportion of identified psychiatric disorders ran a chronic or relapsing course, and that the tendency to chronicity was more marked among female patients. Some confirmatory evidence was provided by an analysis of the course of new psychiatric illness in a subsample of the patient cohort, namely, all those patients first given a psychiatric diagnosis in 1958. These patients were selected because of their freedom from declared psychiatric illness for at least one preceding year. Table III sets out the proportions given a psychiatric diagnosis in one or more of the subsequent survey years.

It is clear from Table III that the rates for declared psychiatric illness in this patient group remained higher for women than for men during the ensuing years. The same point can be expressed by saying

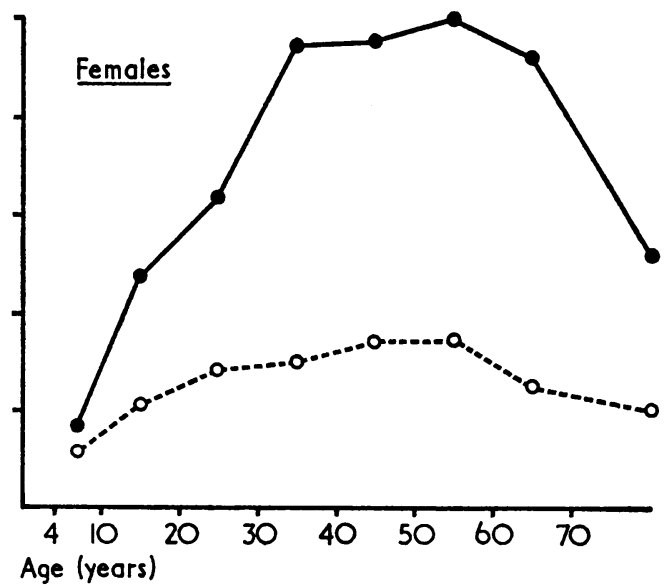

Fig. 4.-Mean annual psychiatric prevalence and inception rates, 1962-63. 
TABLE III

NUMBER OF SUBSEQUENT YEARS IN WHICH PSYCHIATRIC DIAGNOSIS RECORDED, BY SEX: CASES FIRST DIAGNOSED IN 1958

\begin{tabular}{l|c|c}
\hline $\begin{array}{c}\text { No. of Subsequent Years } \\
\text { Psychiatric Diagnosis } \\
\text { Recorded }\end{array}$ & $\begin{array}{c}\text { Male } \\
\%\end{array}$ & $\begin{array}{c}\text { Female } \\
\%\end{array}$ \\
\hline 0 or 2 & $\begin{array}{c}40.3 \\
41.7 \\
18.0\end{array}$ & $\begin{array}{c}21.8 \\
42.8 \\
3,4 \text { or } 5\end{array}$ \\
Total & 100.0 & $\begin{array}{c}35.4 \\
100.0\end{array}$ \\
\hline No. of patients & 72 & 206 \\
\hline \multicolumn{1}{c|}{ Significance test $\chi^{2}=12.03 ; 2$ d.f.; $P<0.01$} \\
\hline
\end{tabular}

that for male patients in this sub-group the probability of being given a psychiatric diagnosis in any one of the later survey years was 0.24 , whereas for females it was $0 \cdot 39$. The difference reflects the less favourable prognosis for female patients.

A similar analysis by age-group, summarized in Table IV, suggested a less favourable outcome with increasing age, but statistical testing failed to confirm the trend.

\section{TABLE IV}

SUBSEQUENT PSYCHIATRIC DIAGNOSIS FOR PATIENTS FIRST DIAGNOSED IN 1958: DISTRIBUTION BY SEX AND AGE

\begin{tabular}{|c|c|c|c|c|}
\hline \multirow{2}{*}{$\begin{array}{l}\text { No. of Subsequent } \\
\text { Years Psychiatric } \\
\text { Diagnosis } \\
\text { Recorded }\end{array}$} & \multicolumn{2}{|c|}{ Male } & \multicolumn{2}{|c|}{ Female } \\
\hline & $\underset{\%}{\text { Under }} 40$ & $\underset{\%}{\text { Over }} 40$ & $\underset{\%}{\text { Under }} 40$ & $\underset{\%}{\text { Over }} 40$ \\
\hline $\begin{array}{l}0 \\
1 \text { or } 2 \\
3,4 \text { or } 5\end{array}$ & $\begin{array}{l}45 \cdot 7 \\
40 \cdot 0 \\
14 \cdot 3\end{array}$ & $\begin{array}{l}35 \cdot 1 \\
43 \cdot 3 \\
21 \cdot 6\end{array}$ & $\begin{array}{l}23 \cdot 5 \\
45 \cdot 9 \\
30 \cdot 6\end{array}$ & $\begin{array}{l}20 \cdot 7 \\
40 \cdot 5 \\
38 \cdot 8\end{array}$ \\
\hline Total & $100 \cdot 0$ & $100 \cdot 0$ & $100 \cdot 0$ & $100 \cdot 0$ \\
\hline No. of patients & 35 & 37 & 85 & 121 \\
\hline Significance test & \multicolumn{2}{|c|}{$\chi^{2}=1.08 ; 2$ d.f., N.S. } & \multicolumn{2}{|c|}{$\chi^{2}=1.49 ; 2$ d.f., N.S. } \\
\hline
\end{tabular}

For the sub-sample as a whole, the proportion given psychiatric diagnoses remained fairly constant year by year, as Table $\mathrm{V}$ illustrates.

TABLE V

PROPORTION OF PATIENTS FIRST GIVEN A PSYCHIATRIC DIAGNOSIS IN 1958 WHO RECEIVED A PSYCHIATRIC

\begin{tabular}{|c|c|c|}
\hline Year & $\underset{\%}{\text { Male }}$ & $\begin{array}{c}\text { Female } \\
\%\end{array}$ \\
\hline $\begin{array}{l}1959 \\
1960 \\
1961 \\
1962 \\
1963\end{array}$ & $\begin{array}{l}26.4 \\
26.4 \\
20.8 \\
22.2 \\
23.6\end{array}$ & $\begin{array}{l}42 \cdot 7 \\
36.4 \\
37 \cdot 4 \\
38.8 \\
40 \cdot 3\end{array}$ \\
\hline No. of patients & 72 & 206 \\
\hline
\end{tabular}

On the other hand, the course and outcome of illness evidently varied, since for neither sex did the pattern of psychiatric episodes in subsequent years conform to a random model. The observed distribution, as can be seen from Table VI, showed an excess both of those who had no subsequent episodes, and of those given a psychiatric diagnosis in four or five subsequent years. This finding is consistent with a range of variation from short-term illnesses of good outcome on the one hand to chronic or frequently recurring conditions on the other.

\section{TABLE VI}

FREOUENCY OF PSYCHIATRIC DIAGNOSIS IN SUBSEOUENT SURVEY YEARS FOR PATIENTS FIRST GIVEN A PSYCHIATRIC DIAGNOSIS IN 1958: COMPARISON OF OBSERVED AND EXPECTED NUMBERS

\begin{tabular}{l|c|c|c|c}
\hline \multirow{2}{*}{$\begin{array}{c}\text { No. of Years in } \\
\text { which Psychiatric } \\
\text { Diagnosis given }\end{array}$} & \multicolumn{2}{|c|}{ Male } & \multicolumn{2}{c}{ Female } \\
\cline { 2 - 3 } \cline { 5 - 6 } & Observed & Expected & Observed & Expected \\
\hline 0 & 29 & $18 \cdot 4$ & 45 & $17 \cdot 4$ \\
1 & 19 & $28 \cdot 9$ & 51 & $55 \cdot 6$ \\
2 & 11 & $18 \cdot 1$ & 37 & $71 \cdot 1$ \\
3 & 8 & $5 \cdot 7$ & 35 & $45 \cdot 5$ \\
4 or 5 & 5 & 0.9 & 38 & 16.4 \\
Total & 72 & 72 & 206 & 206 \\
\hline
\end{tabular}

$\left(\chi^{2}=18.41 ; 2\right.$ d.f. for males; $91.46 ; 3$ d.f. for females; $P<0.01$ for both sexes)

\section{Psychiatric Morbidity and Consultation} PATTERNS

The findings may have been affected by differing consultation habits among the patient cohort. The extent to which consulting patterns reflect patients" habits and attitudes, rather than the distribution of morbidity in the population, cannot be ascertained in a study of this kind, in which no information is available other than that obtained at medical consultation. That psychiatric diagnosis was related to the frequency of consulting can be seen from Table VII.

TABLE VII

TOTAL CONSULTATIONS FOR THE PERIOD 1957-63, BY SEX: (a) FOR PATIENTS GIVEN A PSYCHIATRIC DIAGNOSIS, AND (b) FOR THE REMAINDER OF THE PATIENT COHORT

\begin{tabular}{|c|c|c|c|c|}
\hline \multirow[b]{2}{*}{$\begin{array}{l}\text { No. of } \\
\text { Consultations }\end{array}$} & \multicolumn{2}{|c|}{ Male } & \multicolumn{2}{|c|}{ Female } \\
\hline & $\begin{array}{c}\text { Psychiatric } \\
\text { Patients } \\
\%\end{array}$ & $\underset{\%}{\text { Others }}$ & $\begin{array}{c}\text { Psychiatric } \\
\text { Patients } \\
\%\end{array}$ & $\begin{array}{c}\text { Others } \\
\%\end{array}$ \\
\hline $\begin{array}{l}\text { Under } 10 \\
10-19 \\
20-29 \\
30-39 \\
40 \text { and over }\end{array}$ & $\begin{array}{l}14.5 \\
27.9 \\
22.2 \\
15.0 \\
20.4\end{array}$ & $\begin{array}{r}41 \cdot 1 \\
32 \cdot 2 \\
14 \cdot 3 \\
6 \cdot 2 \\
6 \cdot 1\end{array}$ & $\begin{array}{r}7 \cdot 2 \\
18 \cdot 9 \\
23 \cdot 0 \\
17 \cdot 2 \\
33 \cdot 7\end{array}$ & $\begin{array}{r}33 \cdot 7 \\
30.9 \\
17 \cdot 3 \\
8 \cdot 5 \\
9.6\end{array}$ \\
\hline Total & $100 \cdot 0$ & $100 \cdot 0$ & $100 \cdot 0$ & $100 \cdot 0$ \\
\hline $\begin{array}{l}\text { Mean no. of } \\
\text { consultations }\end{array}$ & $27 \cdot 5$ & $15 \cdot 3$ & $34 \cdot 4$ & $18 \cdot 5$ \\
\hline $\begin{array}{l}\text { Test of difference } \\
\text { between means }\end{array}$ & $z=12 \cdot 2$ & $<<0.01$ & $z=17 \cdot 7$ & $P<0.01$ \\
\hline No. of patients & 481 & 1,544 & 1,048 & 1,170 \\
\hline
\end{tabular}

z is approximately a standard normal deviate 
The relationship is further emphasized by Table VIII, in which the total numbers of consultations over the survey period are related to the number of years in which a psychiatric diagnosis was made.

TABLE VIII

NUMBER OF YEARS IN WHICH PSYCHIATRIC DIAGNOSIS MADE BY TOTAL NUMBER OF CONSULTATIONS, BY SEX

\begin{tabular}{|c|c|c|c|c|c|}
\hline \multirow[b]{2}{*}{$\begin{array}{c}\text { No. of } \\
\text { Consultations }\end{array}$} & \multicolumn{5}{|c|}{ No. of Years given Psychiatric Diagnosis } \\
\hline & $\begin{array}{l}0 \\
\%\end{array}$ & $\frac{1}{\%}$ & $\stackrel{2}{\%}$ & $\begin{array}{l}3 \\
\%\end{array}$ & $\begin{array}{c}4 \text { or } \\
\text { more } \\
\%\end{array}$ \\
\hline $\begin{array}{c}\text { Males } \\
0-19 \\
20+\end{array}$ & $\begin{array}{l}73 \cdot 3 \\
26 \cdot 7\end{array}$ & $\begin{array}{l}51 \cdot 9 \\
48 \cdot 1\end{array}$ & $\begin{array}{l}40 \cdot 2 \\
59 \cdot 8\end{array}$ & $\begin{array}{l}30 \cdot 9 \\
69 \cdot 1\end{array}$ & $\begin{array}{l}13 \cdot 8 \\
86 \cdot 2\end{array}$ \\
\hline Total & $100 \cdot 0$ & $100 \cdot 0$ & $100 \cdot 0$ & $100 \cdot 0$ & $100 \cdot 0$ \\
\hline Significance test & \multicolumn{5}{|c|}{$G=0.56 ; z \geqslant 14.1 * ; P<0.01$} \\
\hline No. of patients & 1,544 & 266 & 102 & 55 & 58 \\
\hline $\begin{array}{c}\text { Females } \\
0-19 \\
20+\end{array}$ & $\begin{array}{l}64 \cdot 5 \\
35 \cdot 5\end{array}$ & $\begin{array}{l}41 \cdot 8 \\
58 \cdot 2\end{array}$ & $\begin{array}{l}28 \cdot 2 \\
71 \cdot 8\end{array}$ & $\begin{array}{l}18 \cdot 4 \\
81 \cdot 6\end{array}$ & $\begin{array}{r}4 \cdot 8 \\
95 \cdot 2\end{array}$ \\
\hline Total & $100 \cdot 0$ & $100 \cdot 0$ & $100 \cdot 0$ & $100 \cdot 0$ & $100 \cdot 0$ \\
\hline Significance test & \multicolumn{5}{|c|}{$G=0.66 ; z \geqslant 14.1 * ; P<0.01$} \\
\hline No. of patients & 1,170 & 402 & 234 & 141 & 271 \\
\hline
\end{tabular}

- An upper bound has been taken for the variance of $G$, so that the level of significance here reported is a conservative estimate. Hence the standard normal deviate, $\mathrm{z}$, is shown as greater than or equal to the test statistic calculated on this basis (see Goodman and Kruskal, 1963)

Table VIII reveals a positive correlation between frequency of consulting and the number of years in which a psychiatric diagnosis was given. The obvious explanation for this finding is that patients with chronic or recurrent psychiatric illness consult their doctors frequently. It can be argued, however, that those patients who for whatever reason maintain a high frequency of consulting are more likely, other things being equal, to be diagnosed as neurotic, and that to this extent the relationship is an artefact.

TABLE IX

FREQUENCY OF HOSPITAL REFERRAL, BY FREQUENCY OF PSYCHIATRIC DIAGNOSIS

\begin{tabular}{|c|c|c|c|c|c|}
\hline \multirow{2}{*}{$\begin{array}{c}\text { No. of Years in } \\
\text { which Hospital } \\
\text { Referral Recorded }\end{array}$} & \multicolumn{5}{|c|}{$\begin{array}{c}\text { No. of Years in which Psychiatric } \\
\text { Diagnosis made }\end{array}$} \\
\hline & $\begin{array}{l}0 \\
\%\end{array}$ & $\frac{1}{\%}$ & $\stackrel{2}{\%}$ & $\begin{array}{l}3 \\
\%\end{array}$ & $\begin{array}{l}4 \text { or } \\
\text { more } \\
\%\end{array}$ \\
\hline $\begin{array}{l}0 \\
1 \\
2 \\
3 \\
4 \text { or more }\end{array}$ & $\begin{array}{r}74 \cdot 4 \\
19 \cdot 7 \\
4 \cdot 3 \\
1 \cdot 2 \\
0 \cdot 4\end{array}$ & $\begin{array}{r}62 \cdot 8 \\
26 \cdot 3 \\
7 \cdot 6 \\
2 \cdot 8 \\
0.5\end{array}$ & $\begin{array}{r}51 \cdot 9 \\
30 \cdot 7 \\
10 \cdot 3 \\
4 \cdot 1 \\
3 \cdot 0\end{array}$ & $\begin{array}{r}46.4 \\
36.1 \\
11.9 \\
5.1 \\
0.5\end{array}$ & $\begin{array}{r}43 \cdot 2 \\
31 \cdot 0 \\
15 \cdot 2 \\
7 \cdot 9 \\
2 \cdot 7\end{array}$ \\
\hline Total & $100 \cdot 0$ & $100 \cdot 0$ & $100 \cdot 0$ & $100 \cdot 0$ & $100 \cdot 0$ \\
\hline Significance test & \multicolumn{5}{|c|}{$G=0.38 ; z \geqslant 10.4 * ; P<0.01$} \\
\hline No. of patients & 2,714 & 668 & 336 & 196 & 329 \\
\hline
\end{tabular}

- See footnote to Table VIII
Whatever the nature of the relationship, the findings point to an identifiable group of patients who were repeatedly given psychiatric diagnoses, and who maintained a high level of demand for medical care. That this demand was not confined to the general medical services can be seen from Table IX, where the distribution of hospital referrals during the survey period is outlined.

\section{Discussion}

In the interpretation of general practice statistics, careful regard must be paid to the validity and reliability of case-identification. In the present instance, some supporting evidence could be adduced for the diagnostic reliability of the practitioners. First, the prevalence and distribution of psychiatric morbidity found in the patient cohort were broadly similar to those reported from a large general practice survey (Shepherd et al., 1966). Both principals had taken part in that survey and their psychiatric case-reporting was known to approximate to the mode for the eighty-odd doctors involved.

Secondly, a study undertaken in the same practice some years earlier (Brown and Fry, 1962) showed that one of the principals agreed well with a trained psychiatrist, and moderately well with the C.M.I. Health Questionnaire, in case-identification.

Thirdly, several follow-up studies carried out on the practice population confirmed that patients diagnosed by the two practitioners consistently exhibited clinical psychiatric disorders when interviewed by trained psychiatrists (Cooper, 1965; Kedward, 1967; Eastwood, 1967).

These studies could not, however, exclude the possibility of under-reporting and it may be that the 'normal' (non-psychiatric) section of the patient cohort actually contained some undiagnosed psychiatric cases. To this extent, the reported prevalence and inception rates may be under-estimates. The matter could be settled only by clinical psychiatric examination of random samples of the population.

No correction factor could be introduced for possible bias in the patient cohort. On the one hand, the high loss of young adults presumably tended to increase the reported prevalence rates, since psychiatric disorder is most common in middle age. On the other hand, loss through geographic mobility would tend to decrease the reported prevalence, inasmuch as mobile patients probably carry a higher risk of psychiatric morbidity than those who are residentially stable (Shepherd et al., 1966).

In the present enquiry, the findings for the 1958 sub-sample broadly substantiate those of the earlier follow-up in the same practice (Fry, 1960). Both emphasize the less favourable prognosis for women 
and the association between psychiatric illness and a persistently raised consultation rate. The proportion of cases found to be active after three years was somewhat lower in this study $(21 \%$ of men and $37 \%$ of women, compared with $27 \%$ and $43 \%$ respectively in the earlier enquiry), a discrepancy which is probably due to the different criteria for selection. In the present instance, the more chronic case-material was largely excluded from the sample chosen for followup.

The follow-up of this sub-sample helps to bring the earlier findings into perspective. The proportion of active cases was just as high after four or five as after three years, and no evidence was found of an over-all trend towards recovery. On further analysis, a sub-group could be discerned, comprising twofifths of the male patients and just over one-fifth of the females, for whom psychiatric diagnosis had been confined to a single year and hence presumably was of good outcome. At the opposite extreme, a distinct sub-group of patients had presented with psychiatric illness in at least four out of five successive years, and could fairly be described as chronic. It is a convenient hypothesis that the former group comprised chiefly 'situational reactions' in relatively stable individuals, while the latter represented some form of constitutional vulnerability.

The large majority of psychiatric cases appeared to be either chronic or recurrent in nature. The fact that their patterns of consultation were so varied and so commonly discontinuous can be explained by either of two simple models. In the first, the patient has a permanently increased susceptibility, but clinical psychiatric states occur as a rule in episodes separated by intervals of comparative normality. In the second, clinical psychiatric morbidity is chronic and continuous but the patient has only intermittent spells of medical care, more or less fortuitously determined. In order to decide which of these models most nearly approximates to the truth, it will be necessary to undertake prospective studies in which fluctuations of psycho-social adjustment can be charted against spells of medical care.

As Kessel (1965) pointed out in relation to his own survey of a general practice population, the type of consulting pattern here displayed goes some way towards explaining the discrepancies in reported follow-up studies of the neuroses. Clearly, according to the operational terms employed and the precise follow-up interval, one might arrive at widely differing estimates of outcome for any given patient cohort.

\section{SUMmary}

Consultation and hospital referral patterns were charted for a cohort of over 4,000 registered general practice patients during a seven-year period. The mean annual prevalence rate for psychiatric morbidity was 60 per 1,000 at risk for males and $172 \stackrel{\%}{\circ}$ per 1,000 for females. The corresponding inception $\overrightarrow{\bar{F}}$ rates, based on average figures for the last two years of the survey, were 32 and 61 per 1,000 respectively.

The prognosis, as gauged by the course of declared illness over the survey period, was found to be more favourable for men than for women, but no significant age difference was established. The patterns of consultation and diagnosis over the years suggested a varying prognosis, with a minority of short-term cases of good outcome and a majority of chronic or recurrent cases. It is hypothesized that the former group was comprised largely of 'situational reactions' and the latter of constitutionally vulnerable individuals.

A clear association was found between the presence of psychiatric disturbance and the patients' rates of consultation and hospital referral. The nature of this relationship remains to be explored.

This study was undertaken with the aid of a grant from the Royal College of General Practitioners and during the tenure by one of us (B.C.) of a Senior Lectureshim supported by the Mental Health Research Fund.

We are grateful to Dr. J. B. Dillane for helpful cor operation, to Miss M. Blake for coding the data, and Miss D. Rockett for much assistance at all stages of the research.

\section{REFERENCES}

Brown, A. C., and Fry, J. (1962). The Cornell Medical Index Health Questionnaire in the identification of neurotic patients in general practice. $J$. psychosom. Res., 6, 185.

COOPER, B. (1965). A study of 100 chronic psychiatric patients identified in general practice. Brit. J. Psychiat. 111, 595.

(1966). Psychiatric disorder in hospital and general practice. Soc. Psychiat., 1, 7.

EASTWOOD, M. R. (1967). Some observations on the natural history of chronic psychiatric illness in general practice. D.P.M. Dissertation. (Unpublished).

ESSEN-MÖLLER, E. (1956). Individual traits and morbidity in a Swedish rural population. Acta psychiat. scand., Suppl. 100.

FRY, J. (1957). Five years of general practice. A study in simple epidemiology. Brit. med. J., 2, 1453.

(1960). What happens to our neurotic patients? Practitioner, 185, 85.

(1966). Profiles of Disease. Livingstone, Edinburgh and London.

Goodman; L. A., and KRUSKal, W. H. (1963). Measures of association for cross classifications. III: Approximate sampling theory. J. Amer. stat. Ass., 58, 310.

Helgason, T. (1964). Epidemiology of mental disorders in Iceland. Acta psychiat. scand., Suppl. 173. 
Kalton, G. (1968). The contribution of research in general practice to the study of morbidity. J. roy Coll. gen Practit., 15, 81.

KEDWARD, H. B. (1967). The natural history of minor psychiatric illness. M.D. Thesis, University of Manchester (Unpublished).

KesseL, N. (1965). The neurotic in general practice. Practitioner, 194, 636.

and SHEPHERD, M. (1962). Neurosis in hospital and general practice. J. ment. Sci., 108, 159.

Leighton, D. C., Harding, J. S., Macklin, D. B., Hughes, C. C., and Leighton, A. H. (1963). Psychiatric findings of the Stirling County Study. Amer. J. Psychiat., 119, 1021.

Pasamanick, B., Roberts, D. W., Lemkau, P. W., and KRUEGER, D. B. (1959). A survey of mental disease in an urban population: prevalence by race and income. In Epidemiology of Mental Disorder. Ed. Pasamanick, B., p. 183. Publication No. 60 of the American Associa- tion for the Advancement of Science, Washington, D.C.

SHEPHERD, M., COOPER, B., Brown, A. C., and Kalton, G. W. (1966). Psychiatric Illness in General Practice. Oxford University Press, London.

Srole, L., Langner, T. S., Michael, S. T., Opler, M. K., and RENNIE, T. A. C. (1962). Mental Health in the Metropolis: The Midtown Manhattan Study. McGraw-Hill, New York.

WatTs, C. A. H. (1962). Psychiatric disorders. In Morbidity Statistics from General Practice. Vol. III (Disease in General Practice), p. 35. The Research Committee of the Council of the College of General Practitioners. General Register Office: Studies on Medical and Population Subjects, No. 14. H.M.S.O., London.

, Cawte, E. C., and Kuenssberg, E. V. (1964). Survey of mental illness in general practice. Brit. med. J., 2, 1351 . 